\title{
Fuzzy Decision Support in the Early Phases of the Fuzzy Front End of Innovation in Product Development
}

\author{
Achiche, Sofiane; Appio, Francesco Paolo
}

Published in:

Proceedings of the ASME 2010 International Design Engineering Technical Conferences \& Computers and Information in Engineering Conference

Publication date:

2010

Document Version

Publisher's PDF, also known as Version of record

Link back to DTU Orbit

Citation (APA):

Achiche, S., \& Appio, F. P. (2010). Fuzzy Decision Support in the Early Phases of the Fuzzy Front End of Innovation in Product Development. In Proceedings of the ASME 2010 International Design Engineering Technical Conferences \& Computers and Information in Engineering Conference: IDETC/CIE 2010

\section{General rights}

Copyright and moral rights for the publications made accessible in the public portal are retained by the authors and/or other copyright owners and it is a condition of accessing publications that users recognise and abide by the legal requirements associated with these rights.

- Users may download and print one copy of any publication from the public portal for the purpose of private study or research.

- You may not further distribute the material or use it for any profit-making activity or commercial gain

- You may freely distribute the URL identifying the publication in the public portal 


\section{DETC2010-वस्पा}

\section{FUZZY DECISION SUPPORT IN THE EARLY PHASES OF THE FUZZY FRONT END OF INNOVATION IN PRODUCT DEVELOPMENT}

\author{
Sofiane Achiche \\ Department of Management Engineering \\ Technical University of Denmark \\ Lyngby, Denmark \\ soac@man.dtu.dk
}

\author{
Francesco Paolo Appio \\ Marketing Department \\ Nestlè Italiana S.p.A. \\ Milan, Italy \\ FrancescoPaolo.Appio@IT.nestle.com
}

\section{ABSTRACT}

The innovation process may be divided into three areas: the fuzzy front end (FFE), the new product development (NPD) process, and commercialization. Every NPD process has a FFE in which products and projects are defined. Companies tend to begin the stages of FFE without a clear definition and analysis of the process to go from opportunity identification to concepts, and often they even abort the process or start over. Koen's Model for the FFE is composed of 5 different phases, the first two being Opportunity Identification and Opportunity Analysis, which are the focus of this paper. Furthermore, several tools can be used by designers/managers in order to improve, structure and organize their work during the FFE. However, these tools tend to be selected and used in a heuristic manner. Additionally, some tools are preferred and more effective during specific phases of the FFE; hence an economic evaluation of the cost of their usage is very critical and there is also a need to characterize them in terms of their influence on the FFE.

This paper focuses on decision support for managers/designers in their process of assessing the cost of choosing/using tools in the core front end activities, namely Opportunity Identification and Opportunity Analysis. This is achieved by analyzing the Influencing Factors (Firm context, Industry context, Macro environment) along with data collection from managers followed by the automatic construction of fuzzy decision support models (FDSM) of the discovered relationships. The decision support focuses upon the estimate investment needed for the use of tools during the 2 phases cited above. The generation of FDSMs is carried out automatically using a specialized genetic algorithm applied to learning data obtained from 5 experienced managers from 5 different companies. The automatically constructed FDSMs accurately reproduced the managers' estimations using the learning data sets and were very robust when validated with hidden data sets.

\section{INTRODUCTION}

The innovation process may be divided into three categories: the fuzzy front end (FFE), the new product development (NPD) process, and commercialization [19]. Attention has been nearly always turned to the efficiency and effectiveness of the NPD activities to set up a good market launch and get adequate payback and return on investments. Nevertheless, the new products failure rate is still high and one of the reasons is the simplistic/fuzzy approach toward the front end analyses.

Every NPD process has a FFE in which products and projects are defined. However, the ways product ideas are generated, developed and assessed varies greatly [19]. The FFE is usually described with two approaches: sequential and nonsequential. Sequential frameworks such as Stage-GateTM model [9] or PACE® (Product and Cycle-time Excellence) model [25] are now sometimes considered as not appropriate. For example, Stage-Gate ${ }^{\mathrm{TM}}$ model focuses on the management of individual or group of projects, not paying attention to links between technology and business opportunities. Hence, projects are often extensions of existing products. According to [27], problems related to the management of multiple projects such as resources competition and sorting out priorities for development cannot be solved by such linear thinking. In view of this fact, it emerges the need to move from a sequential process model to a non-sequential relationship model [19] (see Figure 1) and with it the need for tools to help structuring and decision making. 
Frequently, companies begin the stages of FFE without a clear definition and analysis of the process to go from opportunity identification to concepts, often they even abort the process or to start over. For each stage of the Koen's Model [19] several tools, such as Brain Storming, Mind mapping, etc, exist and can be used by designers to improve, structure and organize their work in the FFE context. However, these tools tend to be selected and used in a heuristic manner, which has a big influence on the total cost of a NPD project, since $70 \%$ of project cost is determined by the decisions made during the FFE [19] and that cost increase whenever there is a loop-back. Furthermore, some tools are preferred and more effective during specific phases of FFE [8]. Hence, economic evaluation of tools' cost becomes very critical. It is therefore needed to characterize the tools in terms of their influence on the FFE and the cost of their usage.

This paper focuses on decision support for managers in their process of assessing the cost of choosing/using tools in the Core Front End "Activity" elements (Opportunity Identification and Opportunity Analysis) as shown in Figure 1. This is achieved by analyzing the Influencing Factors (Firm context, Industry context, Macro environment) and then the construction of fuzzy decision support models (FDSM) of the discovered relationships.

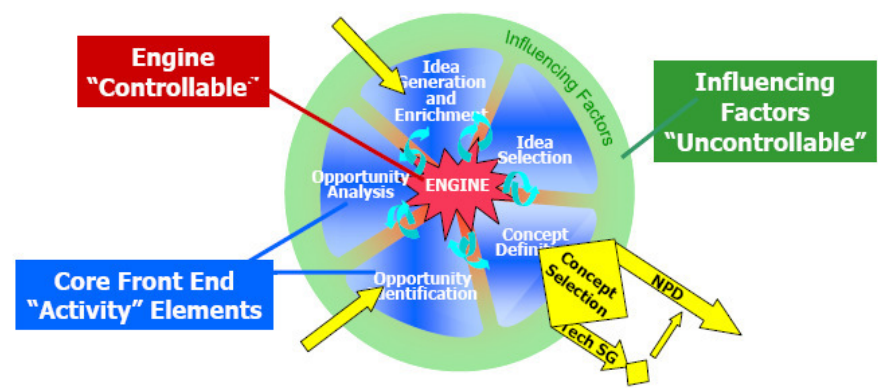

Figure 1: The New Concept Development (NCD) model. (Koen, et al. 2002)

The decision support will focus on the estimate investment needed for the use of tools during the opportunity identification and analysis of the FFE. FDSMs will be linking the parameters of tools in terms of Explicit Costs and Persons to the Estimate Investment of its use, taking into consideration the use intensity of the tool. FDSMs are constructed using Fuzzy-Flou[2].

FDSMs generalize and formalize the manager's assessment (transportable to other managers), and the If-Then fuzzy rules of the FDSMs are explicit and can be used as future decision support rules in the FFE additionally to help to improve the understanding of this less structured phase of NPD. Furthermore, the FDSMs enable a company/manager to understand better the management of its cost structure during the above mentioned phases of FFE.

In this paper 5 different companies were used for the data collection. Furthermore, in order to increase the generalization level of the fuzzy models and to reduce subjectivity, the learning of the FDSMs was carried out using the data from the tools that were selected by the majority of companies ( 3 out of $5)$.

\section{RESEARCH AIM}

The long term aim of this research is to support managers when adopting a tool to use during FFE of innovation through the creation of FDSMs that can be used for the following:

- a starting point for tool adoption/use

- a better distribution of assets (human potential/money) versus cost of tool usage

- analyses of costs during different phases of FFE

The specific research aims for the work presented in this paper is to focus on the opportunity identification and opportunity analysis of the FFE estimate investment.

The inputs of the FDSMs are two macro-parameters namely: Persons and Explicit Costs.

Each considered tool was assessed by the managers against these two macro-parameters, which have a set of microparameters. The FDSMs link inputs of the opportunity analysis and/or opportunity identification phases with an Estimate Investment of using a tool, through the use and evaluation of the dimensions Persons and Explicit Costs. In other words, the micro and macro parameters were used as inputs to FDSMs (rule base and database) while the output being either the Estimate Investment or the cost in Persons and the Explicit Costs. It is noteworthy that in this paper, the developed FDSMs are not tool specific but will be helping the managers decide on the estimate investment for the entire phase.

\section{RESEARCH METHODOLOGY}

The research methodology employed is summarized here. An explorative research to classify the tools was first carried out, from for which 59 existing tools were assessed and considered [4]. It is noteworthy that "Tools" embraces methods, models, systems, frameworks and techniques. Tools were assessed in terms of (Figure 2):

- Inputs, i.e. information, knowledge, procedures;

- Outputs, i.e. products, services, procedures, information, knowledge;

- Resources, i.e. two macro-parameters have been chosen from the analysis of the literature to describe the resource requirements. Both of them, divided into micro-parameters.

The tools were classified according to the categories opportunity analysis and identification proposed by Koen [19]. Figure 1 illustrates the Koen's Model for FFE [19]. 


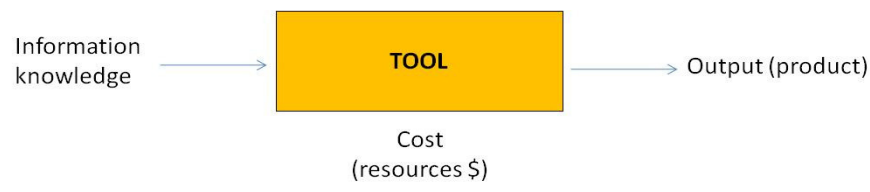

Figure 2: Inputs, Outputs and Resources to use tools

In order to build the link between theory and practice, the case study was carried with 2 Danish and 3 Italian companies. In this paper, the information collection was done by means of a 3 -steps procedure [4] that will be described in the following sections.

\section{DATA COLLECTION}

In order to collect information data from the companies' managers, a semi-structured interview was carried out. Many factors (e.g. available time, factors from inside and outside the work place, the relationship with the interviewer, the respondent's role experience, etc) could influence respondent's answers, and it is very difficult for the interviewer to control them. Given that and in order to reduce the effect of bias, it was decided to proceed using the following three steps.

\subsection{Step 1: Tools reviewing}

A document containing indications about the context of FFE (focus on the Opportunity Identification and Opportunity Analysis stages) and instructions about how to proceed was sent by e-mail, after a brief explanation of the context, to the manager. Then the managers are presented with a table containing all the tools reported by the authors from literature. This table is used to understand if the company uses/knows the tool, in which of the two stages mentioned above, and/or if it is used in combination with other tools. Additionally, the managers could add in tools used within the organization and not listed in the table.

The aim of the step 1 is to map the tools' usage inside the companies' practices and processes and to discover other tools that did not emerge from the literature review.

\subsection{Step 2: Mapping Inputs and Outputs}

This step is a semi-structured interview that was carried out face-to-face (at the company's office), or via Skype.

The semi-structured interview used the last incident method as a starting point, followed by more specific questions about key FFE's parameters, to finally end with questions about the tools. The aim of this step is to have an in depth description of the environment in which the interviewee operates, to release further comments about step 1, to understand if the process is structured or not and to draw a comprehensive mapping of the inputs and outputs of tools.

\subsection{Step 3: Usage Intensity and Parameters Assessment}

This step was carried out via e-mail. In this part the manager stated the use intensity of each tool using a Likert scale
1-5. This was followed by an assessment of the parameters and micro-parameters, with a focus on the rate incidence (\%) given by the interviewee during the interview. The aim of this step is to formalize results about the usage of resources implied by adopting a specific tool, which later can be generalized for a phase.

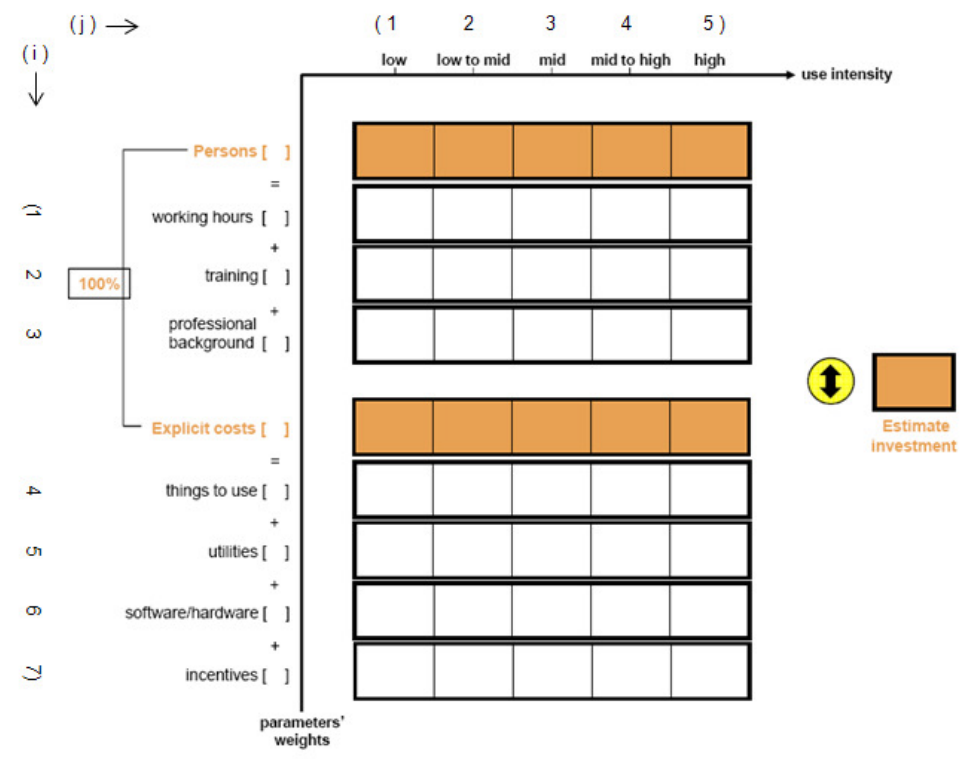

Figure 3: Final Evaluation Card

After these three steps the results were summarized in a matrix called Final Evaluation Card (see Figure 3) this is composed of two axes, the vertical one for indicating the parameters' weights, and the horizontal one to represent the use intensity; two grids are constructed to obtain the Estimate Investment (qualitative evaluation) related to a single tool. More details will be given later in this paper.

\section{REVIEW OF TOOLS USED IN OPPORTUNITY IDENTIFCATION AND ANALYSIS}

From the literature review many tools used in the first two stages of the FFE emerged. In this section a clustering of these tools will be carried out in order to ease their analysis and assessment. Some of the methods utilized in the Opportunity Identification stage (structured approach) are Customer trend analysis, Road mapping, Technology trend analysis etc., whereas, it is possible to conduct analysis of the same stage in an informal way with tools such as Ad hoc sessions, Water Cooler, etc. [19].

In the Opportunity Analysis stage it is possible to use the same tools as in the Opportunity Identification stage [19] and based on this the data collection from all the tools in both stages will be merged to form the learning data file for FDSM construction. Table 1 gives a short example of the tools' clustering for each phase and their description. Each manager received a copy of the table. 
Table 1. Clustering of tools

\begin{tabular}{|c|c|c|c|c|}
\hline $\begin{array}{l}\text { Stage of the } \\
\text { NCD model }\end{array}$ & Context & Tool & $\begin{array}{l}\text { Short } \\
\text { description }\end{array}$ & References \\
\hline $\begin{array}{l}\text { Opportunity } \\
\text { Identificatio } \\
\text { n }\end{array}$ & $\begin{array}{l}\text { Technologies } \\
\text { trend } \\
\text { analysis } \\
\\
\text { Market } \\
\text { research }\end{array}$ & $\begin{array}{l}\text { S-curve } \\
\\
\\
\text { Standard } \\
\text { and } \\
\text { dominant } \\
\text { design } \\
\quad \ldots .\end{array}$ & $\begin{array}{l}\text { Technology has } \\
\text { a life cycle } \\
\text { interpreted by a } \\
\text { curve that } \\
\text { follows an } \\
\text { empirical law. } \\
\text { It can explain } \\
\text { trends about } \\
\text { technologies' } \\
\text { adoption, } \\
\text { improvement } \\
\text { and diffusion. } \\
\qquad . . \\
\text {... }\end{array}$ & $\begin{array}{l}{[5]} \\
\text { [34] }\end{array}$ \\
\hline $\begin{array}{l}\text { Opportunity } \\
\text { Analysis }\end{array}$ & $\begin{array}{l}\text { Creative } \\
\text { thinking } \\
\text { Investment } \\
\text { analysis }\end{array}$ & $\begin{array}{l}\text { Brain } \\
\text { Storming } \\
\\
\\
\\
\text { TRIZ }\end{array}$ & $\begin{array}{l}\text { It is defined as } \\
\text { a semi- } \\
\text { structured } \\
\text { activity of a } \\
\text { team. Its aim is } \\
\text { to stimulate the } \\
\text { idea generation } \\
\text { in a "double- } \\
\text { funnel" } \\
\text { process. They } \\
\text { have also been } \\
\text { described the } \\
\text { Brainwriting } \\
\text { and the Mind } \\
\text { Mapping } \\
\text { techniques. } \\
\quad . .\end{array}$ & $\begin{array}{l}{[40]} \\
{[3]}\end{array}$ \\
\hline
\end{tabular}

\subsection{Qualitative assessment of tools}

After the assessment of the usage of tools by the managers, a qualitative assessment is performed by the authors in terms of input/resources/output as shown in Table 2. This step was carried out for all the tools considered in this research.

Once all the tools were characterized, the authors carried out a classification of inputs, outputs and resources with the aim to find cluster dimensions (macro and micro parameters) that represent the most important characteristics to consider as inputs and outputs for the FDSMs.
Table 2. Tools characterization

\begin{tabular}{|c|c|c|c|}
\hline Tool/Stage & Inputs & Resources & Outputs \\
\hline $\begin{array}{l}\text { CUSTOMER } \\
\text { TREND } \\
\text { ANALYSIS }\end{array}$ & & & \\
\hline $\begin{array}{l}\text { Category } \\
\text { appraisal } \\
\text { (Segmentation) } \\
\text { OI }\end{array}$ & $\begin{array}{l}\text {-customer- } \\
\text { based } \\
\text { approach } \\
\text {-product-based } \\
\text { approach } \\
\text {-dependent } \\
\text { variables } \\
\text {-independent } \\
\text { variables } \\
\text {-questionnaire } \\
\text {-interview } \\
\text {-techniques }\end{array}$ & $\begin{array}{l}\text {-PERSONS } \\
\text {-working hours } \\
\text {-time to decide what } \\
\text { data will be collected, } \\
\text {-time to decide how } \\
\text { data will be gathered } \\
\text { - ... } \\
\text {-training } \\
\text {-professional } \\
\text { background } \\
\text {-marketing analysts } \\
\text {-customer } \\
\text { analysts service } \\
\text {-EXPLICIT COSTS } \\
\text {-things to use } \\
\text {-audio recorder (for } \\
\text { interview) } \\
\text {-utilities } \\
\text {-room } \\
\text {-software/hardware } \\
\text {-software } \\
\text {-PC } \\
\text {-incentives } \\
\text { - correlations with } \\
\text { firms' results }\end{array}$ & $\begin{array}{l}\text {-complete } \\
\text { definition of } \\
\text { each } \\
\text { segment } \\
\text {-profile of } \\
\text { each } \\
\text { segment } \\
\text { (give } \\
\text { name) a }\end{array}$ \\
\hline
\end{tabular}

The clusters in terms of macro and micro parameters will serve as inputs and outputs for the FDSMs. From the understanding of inputs and outputs of the tools used in Opportunity analysis and Opportunity identification the parameters that better depicted the resources consumption were defined. The classification carried out by the authors gave the following results:

- Persons

- Working hours

- Training

- Professional background

- Explicit Costs

- $\quad$ Things to use

- Utilities

- Software/Hardware

- Incentives

In the first macro parameter Persons, "Working hours" refers to the hours dedicated from workers e.g. to select participants in workshops, to collect data, to analyze results, etc. "Training" refers to the necessary amount of hours to give adequate instructions, information or knowledge in order to perform a particular role e.g. in the conduction of a brainstorming session, etc. "Professional background" is a qualitative parameter, but it is possible to transform it in a quantitative one by means of simple data manipulations for instance comparing the background of the participant in comparison to what would be needed to use the tool efficiently, 
for example in order to use tools about category appraisal efficiently, the participant should have marketing analysts background, and customer service analysts skills.

The second macro-parameter is Explicit Costs, where "Things to use" refers to things such as paper, pens, pencils, audio recorder, etc., that could be needed during the use of a specific tool. "Utilities" refers to room availability, internet connection, whiteboards, tables, etc. while "Software/hardware" is related to the use of things like Office suite, printers, etc., as support to the decisions. Finally, "Incentives" refer to financial incentives to participate and/or adopt a specific tool. When implemented in an FDSM, the macro parameters will be the output of the models while the micro parameters will be the inputs. The next step is using Persons and Explicit Costs as inputs for the Estimate Investment. More details will be given in the following sections.

\section{CASE STUDY AND RESULTS}

In the experimental assessment of this paper, 5 companies were used. The managers with whom the project was conducted, their roles in the companies are described in the Table 3:

Table 3. List of companies

\begin{tabular}{|l|l|l|l|l|}
\hline $\begin{array}{l}\text { Company } \\
\#\end{array}$ & $\begin{array}{l}\text { Locatio } \\
\mathbf{n}\end{array}$ & Industry & $\begin{array}{l}\text { Experienc } \\
\text { e }\end{array}$ & $\begin{array}{l}\text { Representative's } \\
\text { role }\end{array}$ \\
\hline 1 & DK & $\begin{array}{l}\text { Engineering } \\
\text { Consultancy }\end{array}$ & 25 years & $\begin{array}{l}\text { Senior Engineer \& } \\
\text { Manager }\end{array}$ \\
\hline 2 & IT & $\begin{array}{l}\text { Engineering } \\
\text { Handicraft }\end{array}$ & 8 years & Export Manager \\
\hline 3 & IT & $\begin{array}{l}\text { Plant } \\
\text { Protection }\end{array}$ & 13 years & R\&D Manager \\
\hline 4 & IT & ICT & 8 years & $\begin{array}{l}\text { Project Engineer } \\
\text { Manager }\end{array}$ \\
\hline 5 & DK & Healthcare & 9 years & $\begin{array}{l}\text { R\&D Innovation } \\
\text { Manager }\end{array}$ \\
\hline
\end{tabular}

\subsection{Parameter selection for decision support}

As stated in the section above, the parameters obtained from the assessment of the tools will be used as inputs for the FDSM. The FDSMs developed in this paper are of the MISO (multiple inputs/single output) type. The following sets of inputs/outputs are considered:

\section{FDSM 1}

- Inputs

- Working hours

- Training

- Professional background

- Output

\section{FDSM 2}

- Persons (investment)

- Inputs

- Things to use

- Utilities
- Software/Hardware

- Incentives

- Output

\section{FDSM 3}

- Explicit Costs

- Inputs

- Persons

- Explicit Costs

- Output

- Estimate Investment

It is noteworthy that FDSM1, FDSM2 and FDSM3 are not tool specific but applied to the stage of opportunity analysis and identification as a whole, which is the focus of this paper as previously stated. However, the same approach can be used for the construction of tool-specific FDSMs; but more experimental data need to be collected, from more companies or more managers, in order to diversify the data and increase the generalization level of the FDSMs. The FDSMs are expected to closely match the managers' evaluations which would lead to a tool that can be used for decision support by other managers. Figure 4 illustrates the schematics of the Manager's fuzzy decision support system, where the manager starts with a request to the system in terms of observations on the inputs which will provide information on Persons investments and/or Explicit Costs, further up the model an Estimate Investment of the phase can be obtained using the output from the previous models.

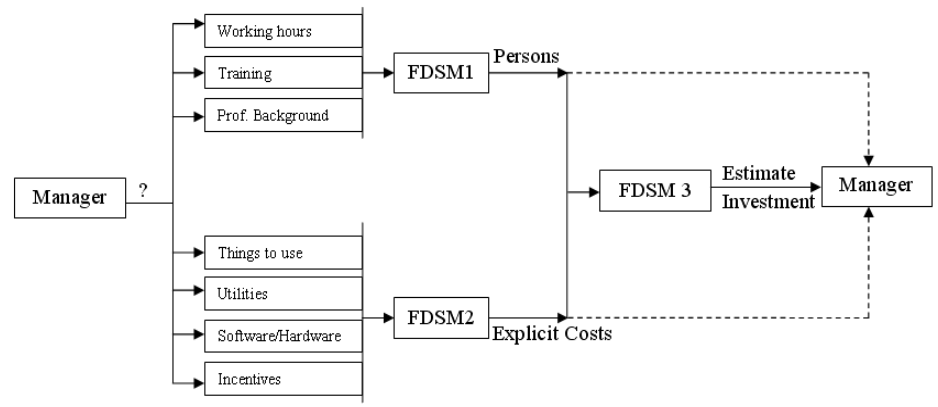

Figure 4: Schematics of the Managers Fuzzy Decision Support System

\subsection{Fuzzy Decision Support Models}

In this section, the construction of the FDSM models will be explained. In order to increase the generalization value of the models, only data from tools that were used by the majority of the companies is included in the learning of the FDSMs. In this paper this means at least three companies have reported using the tool. Furthermore, at least one of the three companies has to be either in Denmark or Italy (IT or DK). Additionally, the tools can be used either in the opportunity analysis phase, the opportunity identification phase or both. The tools meeting these constraints are listed in Table 4. 
Table 4. Tools meeting the constraints for model construction

\begin{tabular}{|l|l|l|}
\hline Tool & Usage & Country \\
\hline Brainstorming [31] & 4 & 2 IT + 2 DK \\
\hline SWOT Analysis [21] & 4 & 2 IT + 2 DK \\
\hline Mind Mapping [36] & 3 & 1 IT + 2 DK \\
\hline Science and Technology Road Mapping [20] & 3 & 2 IT + 1 DK \\
\hline $\begin{array}{l}\text { Corporate or Product Technology Road } \\
\text { Mapping [20] }\end{array}$ & 3 & 2 IT + 1 DK \\
\hline Category Appraisal [26] & 3 & 2 IT + 1 DK \\
\hline
\end{tabular}

The remaining data from the tools that do not meet the constrains cited above, will be used a posteriori for validation of the automatically generated models.

\subsection{Construction of the learning Data Sets}

In order to understand how the data was gathered let us go through an example with one company. In this case company "1" will be used. In order to gather quantitative data, a formalization of results is carried out in terms of resources requirements per tool. The results can help the company to take into consideration the distribution and allocation of resources as estimated by the manager (e.g. spotting inefficient allocation of resources). Company 1's Persons and Explicit Costs parameters usage are illustrated in Figure 5.

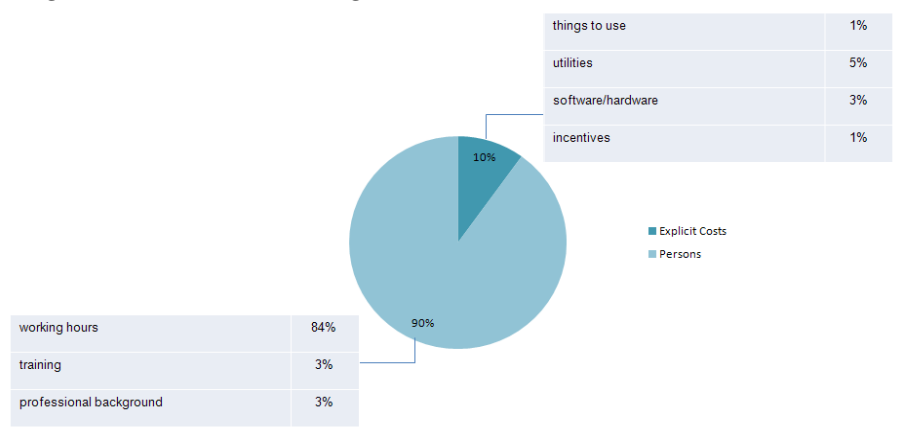

Figure 5: Incidence rate of Explicit Costs and Persons on the company 1's budget

The Persons' micro-parameters are expressed in terms of TIME. However the Explicit Costs' micro-parameters are expressed in terms of MONEY within the company. Considering the budget dedicated to the early stages of the Fuzzy Front End, the higher incidence is given by the macroparameter Persons.

Furthermore, for each tool the company's manager had to state the intensity of use of the tools based on a Likert scale 1-5, where 1 means Low Use Intensity and 5 means High Use Intensity. Figure 6 shows an example for the tool Brainstorming.

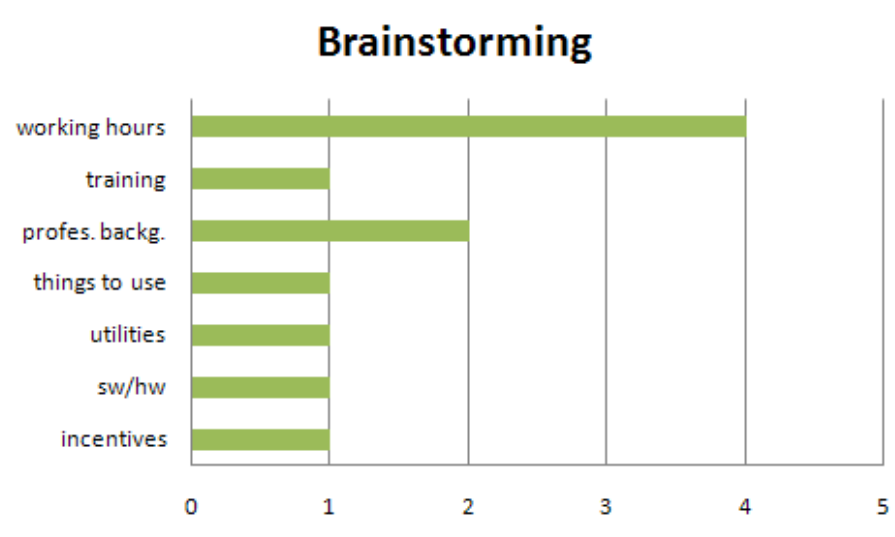

Figure 6: Company 1's manager Use Intensity levels for
Brainstorming

Finally, the information collection is organized by the mean of the 3rd step where the data is formalized. The third step aims at formalizing the resource requirements. The formalization is done by a matrix called Final Evaluation Card (FEC), thanks to which it is possible to calculate the Estimate Investment (EI) per tool according to the following formula:

$\sum_{i=1}^{7} w_{i}\left(\sum_{j=1}^{k} l_{j k}\right)=l_{E I}$

where:

$\mathrm{i}=1 \ldots 7$ (micro-parameters in the FEC)

$\mathrm{j}=1 \ldots 5$ (Use Intensity levels)

$\mathrm{k}=$ the selected Use Intensity level in the FEC

$\mathrm{w}_{\mathrm{i}}=$ micro-parameters' weights

$1_{\mathrm{jk}}=$ resultant Use Intensity level with the cumulative function

$1_{\mathrm{EI}}=$ Estimate Investment level

The values obtained by equation 1 , are used as the output training value levels for the FDSM 3 while the intermediate results are used for FDSM 1 and FDSM 2 (see Figure 4). The approach described above was carried out for each company and tool and used to build up the training set for FDSMs learning.

\subsection{Automatic learning and Generation of FDSM}

The construction of the FDSMs is carried out automatically using a specialized genetic algorithm (GA). GAs are powerful stochastic optimization techniques based on the analogy of the mechanics of biological genetics and imitate the Darwinian survival of the fittest approach [12]. Each individual of a population is a potential FDSM, where four basic operations of the Real/Binary-Like Coded GA (RBCGA) learning are performed; reproduction, mutation, evaluation and natural selection. The RBCGA developed by the authors combines a real coded and a binary coded GA. The reproduction 
mechanisms are a multi-crossover proposed by the authors [2] and a uniform mutation [10].

\subsubsection{Performance Criterion of the RBCGA}

In this paper, the performance criterion is the accuracy level of the FDSMs (approximation error) in reproducing the outputs of the learning data. The approximation error is a combination between the $\Delta_{\mathrm{RMS}}$, measured using the RMS error method and the absolute error, $\Delta_{\mathrm{ABS}}$ the next two equations detail these errors.

$$
\Delta_{\mathrm{R} M S}=\sqrt{\sum_{i=1}^{N} \frac{\left(R B C G A_{\text {output }}-\text { data }_{\text {output }}\right)^{2}}{N}}
$$

While the absolute error is measured as follows:

$$
\Delta_{A B S}=\sum_{I}^{N} A B S\left(\frac{R B C G A_{\text {output }}-\text { data }_{\text {output }}}{N}\right)
$$

where $\mathrm{N}$ represents the size of the learning data. The fitness value $\phi$ is evaluated as a percentage of the output length of the conclusion L, i.e.

$\phi=\left(1-\frac{\Delta_{\mathrm{RMS}}+\Delta_{\mathrm{ABS}}}{2 L}\right) \times 100$

\subsubsection{Evolutionary strategy}

To generate the FDSMs using the RBCGA one has to set up the maximal complexity allowed, the multi-crossover probability and the mutation probability. In this paper the maximal complexity is 5 fuzzy sets per input premise and 12 fuzzy sets on the output. However the RBCGA can reduce those values. The reproduction probabilities are set to: $85 \%$ multicrossover, $15 \%$ simplification rate and 5\% mutation, more details on these mechanisms are given in [1]. The simplification $\%$ is there in order to reduce the complexity of the fuzzy models and increase their generalization level. The population size is set to 200 and the number of generations to 200. Each run was repeated three times to ensure the robustness of the learning process. At the end of the learning the best individual is selected according to the highest $\phi$.

\subsection{Fuzzy Decision Support Models}

The genetically generated FDSM 1 and FDSM 2, were obtained with a fitness function value of $99 \%$, the maximum absolute errors were 0.18 and 0.16 for FDSM1 and 2 respectively. The RBCGA proposed several FDSMs with a high fitness function value, however the selected ones were the ones with the least number of rules. Both FDSM 1 and 2 have only 2 membership functions per premise: high and low. The outputs consist of 7 fuzzy sets namely: Very Little, Small, Low,
Moderate, Modest, Considerable and Very Sizeable. Figure 7 and Figure 8 show FDSM for the Persons and Explicit Costs macro-parameters, the two FDSMs presented here constitute the first two models of the Manager Support System presented in Figure 4.
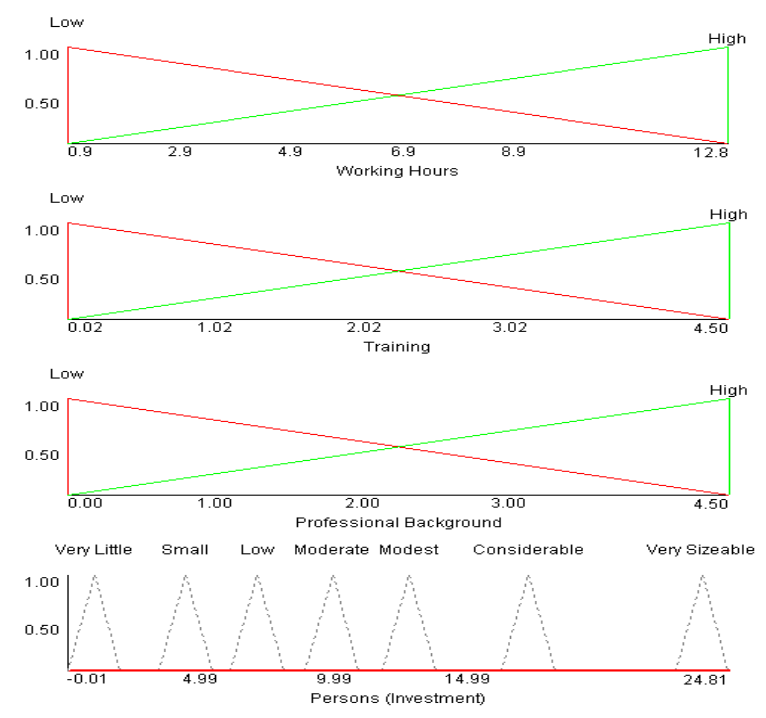

Inference: SUM.PROD. Defuzzification: COA Certainty factors
Aggregation: MIN Propagation: MIN Fusion: MAX TNorm: MIN
Certainty Threshold: 0.000

Figure 7: Persons FDSM (FDSM 1)
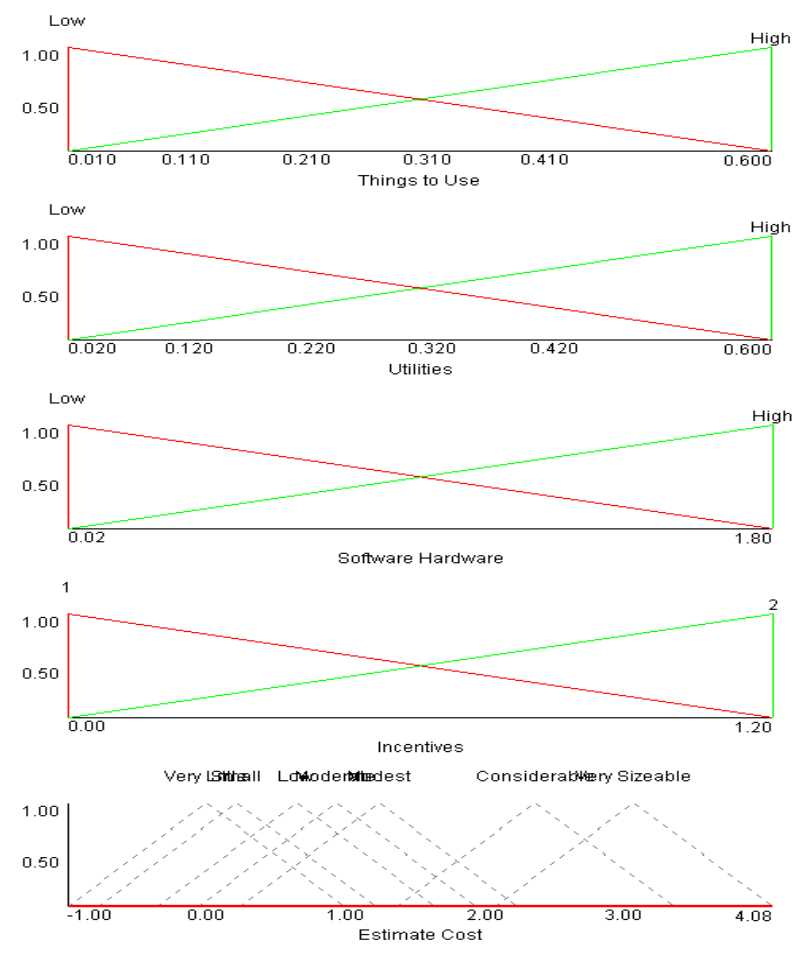

Figure 8: Explicit Costs FDSM (FDSM 2) 
The third FDSM (FDSM 3) is the global model that takes as inputs the values obtained from the FDSM 1 and 2. However the manager can use it individually to assess the estimate investment in tools during the opportunity analysis and/or opportunity identification phases.
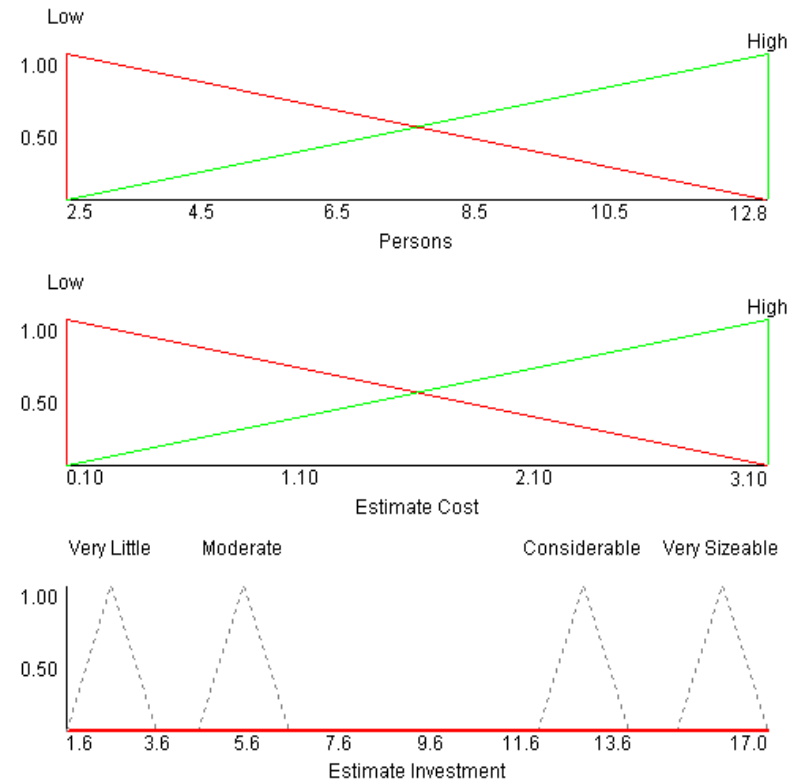

Figure 9: Estimate Investment FDSM (FDSM 3)

FDSM 3 contains two fuzzy sets on the inputs Persons and Estimate Cost namely High and Low, while on the output four fuzzy sets were enough to model the experimental data: Very Little, Moderate, Considerable and Very Sizeable. FDSM 3 was generated with an accuracy of $99 \%$ while reproducing the experimental data. The maximum absolute error for FDSM 3 is 0.26 .

The advantage of FDSMs is that the manager can both enter crisp observations in order to predict one of the macroparameters or use fuzzy sets as inputs and hence add uncertainty to his observations and still get a crisp value as an output. Figure 9 illustrates FDSM 3 which represents the last part of the Manager Support System presented in Figure 4.

As one can see from Figure 7, Figure 8 and Figure 9 the FDSMs are totally transparent, which means that the mangers that will use the models can at the same time understand the relationships between the different inputs and outputs through the analysis of the explicit if-then fuzzy rules. The semantics linked to the FDSMs through the fuzzy sets help giving a human assessment of the estimate investment during critical FFE stages.

\subsection{Validation of the FDSMs Using Hidden Data}

As cited above, the learning was done using five different tools, however during the case study several other tools were listed by the managers as being used but they did not fulfill the generalization constrains the authors set-up in order to be included in the learning set of FDSMs. In this section the data from these tools will constitute the hidden data.

The hidden data will test the robustness of developed FDSMs. Table 5 lists all the tools used for constructing the validation data set along with the frequency of their usage.

Table 5. Tools for model validation

\begin{tabular}{|c|c|c|}
\hline Tool & Usage & Country \\
\hline QFD [39] & 2 & $1 \mathrm{IT}+1 \mathrm{DK}$ \\
\hline PFMP [15] & 1 & $0 \mathrm{IT}+1 \mathrm{DK}$ \\
\hline Ideal Concepts [24] & 1 & $0 \mathrm{IT}+1 \mathrm{DK}$ \\
\hline Analogical Thinking [11] & 1 & $0 \mathrm{IT}+1 \mathrm{DK}$ \\
\hline Morphological Analysis [29] & 1 & $0 \mathrm{IT}+1 \mathrm{DK}$ \\
\hline TRIZ [40] & 2 & $1 \mathrm{IT}+1 \mathrm{DK}$ \\
\hline KJ-Method [28] & 1 & $0 \mathrm{IT}+1 \mathrm{DK}$ \\
\hline Design for $\mathrm{X}[38]$ & 1 & $0 \mathrm{IT}+1 \mathrm{DK}$ \\
\hline Elicitation [36] & 2 & $2 \mathrm{IT}+0 \mathrm{DK}$ \\
\hline Alien Interviewing [23] & 2 & $1 \mathrm{IT}+1 \mathrm{DK}$ \\
\hline Competitive Intelligence Analysis [17] & 2 & $1 \mathrm{IT}+1 \mathrm{DK}$ \\
\hline Porter's Five Forces [14] & 2 & $1 \mathrm{IT}+1 \mathrm{DK}$ \\
\hline Blue Ocean Strategy (Strat. Canvas) [18] & 2 & $1 \mathrm{IT}+1 \mathrm{DK}$ \\
\hline Scenario Planning [35] & 2 & $1 \mathrm{IT}+1 \mathrm{DK}$ \\
\hline Conjoint Analysis [13] & 2 & $1 \mathrm{IT}+1 \mathrm{DK}$ \\
\hline IT Road Mapping [20] & 2 & $1 \mathrm{IT}+1 \mathrm{DK}$ \\
\hline PPM Road Mapping [20] & 2 & $1 \mathrm{IT}+1 \mathrm{DK}$ \\
\hline PEST Analysis [16] & 2 & $1 \mathrm{IT}+1 \mathrm{DK}$ \\
\hline Investment Analysis [3] & 2 & $1 \mathrm{IT}+1 \mathrm{DK}$ \\
\hline AHP [36] & 1 & $1 \mathrm{IT}+0 \mathrm{DK}$ \\
\hline Random Word [30] & 1 & $0 \mathrm{IT}+1 \mathrm{DK}$ \\
\hline Brain writing [36] & 1 & $0 \mathrm{IT}+1 \mathrm{DK}$ \\
\hline Value Appropriation Methods [33] & 1 & $0 \mathrm{IT}+1 \mathrm{DK}$ \\
\hline GE Matrix [21] & 1 & $0 \mathrm{IT}+1 \mathrm{DK}$ \\
\hline BCG Matrix [21] & 1 & $0 \mathrm{IT}+1 \mathrm{DK}$ \\
\hline S Curve [5] & 1 & $0 \mathrm{IT}+1 \mathrm{DK}$ \\
\hline Nominal Group Technique [32] & 1 & $0 \mathrm{IT}+1 \mathrm{DK}$ \\
\hline Lead User Technique [22] & 1 & $0 \mathrm{IT}+1 \mathrm{DK}$ \\
\hline Focus Group [6] & 2 & $1 \mathrm{IT}+1 \mathrm{DK}$ \\
\hline
\end{tabular}

Once the data merged into three different validation files (for FDSM1, FDSM2 and FDSM3), the absolute error profile and the correlations between fuzzy prediction and human evaluation are shown in Table 6. 
Table 6. Error and correlations between fuzzy and human predictions

\begin{tabular}{|l|l|l|l|}
\cline { 2 - 4 } \multicolumn{1}{c|}{} & $\begin{array}{l}\text { Max Absolute } \\
\text { Error }\end{array}$ & $\begin{array}{l}\text { Mean Absolute } \\
\text { Error }\end{array}$ & Correlations \\
\hline FDSM1 Persons & 0.41 & 0.10 & $99 \%$ \\
\hline $\begin{array}{l}\text { FDSM2 Estimate } \\
\text { Cost }\end{array}$ & 0.42 & 0.12 & $99 \%$ \\
\hline $\begin{array}{l}\text { FDSM3 Estimate } \\
\text { Investment }\end{array}$ & 2.78 & 0.81 & $96.3 \%$ \\
\hline
\end{tabular}

One can easily see from Table 6 that the mean absolute error is still low. even when the FDSMs were tested with hidden data. FDSM 1 and 2 predicted the human decision with $99 \%$ correlation. a maximum absolute error of 0.42 and the mean absolute error of 0.12 . FDSM3 performs a bit less accurately with a maximum absolute error of 2.78 on a scale of 15 . However, the average absolute error remains quite low with 0.81 and the correlation high with $96.3 \%$.

\section{CONCLUSION}

This paper presented three different fuzzy logic decision support models for evaluating costs in terms of Persons, Explicit Costs and Estimate Investment needed for using support tools during the early stages of the fuzzy front end of product development. Each of the models was a multiple input single output fuzzy knowledge bases. The fuzzy models were constructed using quantitative data collected form a case study carried out with 5 experienced managers from 5 different companies situated in Denmark or Italy. The obtained results confirm the possibility of estimating the costs of the usage of tools to structure the fuzzy front end of innovation during the opportunity identification and opportunity analysis phases. The three automatically generated fuzzy decision support models developed here matched the managers' evaluations of the investigated dimensions in the learning phase and remained very stable when validated with the hidden data that was not included in the learning set. When selecting fuzzy decision support models from the final population of the genetically generated solutions, the authors favoured smaller and more simple rule bases because they can be more easily investigated by managers in order to understand the influence of the inputs on the outputs and hence better manage the cost of a specific phase in relation to the use of a specific support tool. The approach adopted in this paper can easily be extended to the other phases of the fuzzy front end, and can both be applied to a single tool or an entire phase.

\section{ACKNOWLEDGMENTS}

The authors want to thank all the participants to the case conducted in this paper.

\section{REFERENCES}

[1] Achiche, S., Balazinski, M., \& Baron, L. (2004). Multicombinative Strategy to Avoid Premature Convergence in Genetically-generated Fuzzy Knowledge Mechanics. Journal of Theoretical and Applied Mechanics, vol. 42, $n$. 3 , pp. 417-444.

[2] Achiche, S., Baron, L., \& Balazinski, M. (2003). Real/Binary Like Coded Genetic Algorithm to Automatically Gneerate Fuzzy Knowledge Bases. IEEE Frouth International Conference on Control and Automation (pp. 799-803). Montreal, Canada.

[3] Anthony, R., Hawkins, D., \& Macrì, D. (2005). Sistemi di Controllo. Analisi economiche per le decisioni aziendali. 2nd ed.: McGraw-Hill.

[4] Appio, F. (2009). Managing the Early Stages of the Fuzzy Front End of Innovation: How Companies Use Tools to Identify and Analyze Opportunities. Master Thesis, Department of Management Engineering, Technical University of Denmark, Copenhagen.

[5] Brown, R. (1992). Managing the "S" curves of innovation. Journal of Consumer Marketing, vol. 9, issue 1 .

[6] Bruseberg, A., \& McDonagh, P. (2002). Focus groups to support the industrial/product designer: a review based on current literature and designers feedback. Applied Ergonomics, vol. 33 .

[7] Bsalazinski, M., Bellerose, M., \& Czogala, E. (1993). Application of Fuzzy Logic Techniques to the Selection of Cutting Parameters in Machining Processes. International Journal of Fuzzy Sets and Systems, vol. 61, pp. 307-317.

[8] Commission, E., \& Innova, E. (2008). Insights on Innovation Management in Europe. Tangible Results From IMP3rove.

[9] Cooper, R. (2001). Winning at New Products. Cambridge: Perseus Publishing.

[10] Cordòn, O., Herrera, F., \& Villar, P. (2000). Analysis and Guidelines to Obtain a Good Uniform Fuzzy Partition Granularity for Fuzzy-rule Based Systems using Simulated Annealing. International Journal of Approximate Reasoning , pp. 187-216.

[11] Dahl, D., \& Moreau, P. (2002). The Influence and Value of Analogical Thinking During New Product Ideation. Journal of Marketing Research, vol. 39 .

[12] Goldberg, D. (1989). Genetic Algorithms in Search, Optimization and Machine Learning. Massachussetts: Addison-Wesley.

[13] Green, P., \& Srinivasan, V. (1990). Conjoint Analysis in Marketing: New Developments With Implications for Research and Practice. Journal of Marketing, $n$. 54 .

[14] Grundy, T. (2006). Rethinking and reinventing Micheal Portr's five forces model. Strategic Change, August .

[15]IPU, YORK, \& PTC. (2005). Lean Product Structures. Case: YORK. Denmark.

[16] Jones, K. (2007). PEST or STEP analysis. Retrieved from http://202.205.89.79/download/materials/2007f/discipline/ 
Marketing/Kevin\%20Jones/2b.\%20PEST\%20or\%20STEP $\% 20$ Analysis.ppt

[17] Kahaner, L. (1998). Competitive Intelligence: How to Gather, Analyze and Use Information to Move Business to the Top. New York: Touchstone Books.

[18] Kim, W., \& Mauborgne, R. (2007). Strategia Oceano Blu. Vincere senza competere. Harvard Business School Press, ETAS.

[19] Koen, P., \& al., e. (2002). Fuzzy Front End: Effective Methods, Tools and Techniques. In P. Belliveau, A. Griffin, \& S. Somermeyer, PDMA Toolbook fr New Product Development. New York: John Wiley and Sons.

[20] kostoff, R., \& Schaller, R. (2001). Science and Technology Roadmaps. IEEE Transactions on Engineering Management, vol. 48, n. 2 .

[21] Kotler, P., \& Scott, G. (1993). Marketing Management. Analisi, Pianificazione, Attuazione e Controllo. 7th ed.: Prentice Hall International, ISEDI.

[22] Lilien, G., \& al., e. (2002). Performance Assessment of the Lead User Idea-Generation Process for New Product Development. Management Science, vol. 48, n. 8 .

[23]List, D. (2005). Market research methods for innovation development: an overview. Retrieved from http://www.emarketing.net.cn/upload/file/2009/02/05/1612 33822055976.pdf

[24] McAloone, T., \& Bey, N. Environmental improvement through product development. Denmark.

[25] McGrath, M., \& Akiyama, C. (1996). PACE: An Integrated Process for Product and Cycle Time Exellence. In $\mathrm{M}$. McGrath, Setting the PACE in Produc Development. Boston: Butterworth and Heinemann.

[26] Myers, J. (1996). Segmentation and Positioning for Strategic Marketing Decisions. Chicago, Illinois: American Marketing Association.

[27] Nelson, B. (2004). What Comes After Stage-gate: The Need for a New Framework for Innovation. Retrieved from http://www.workingforums.com/articles/Article3.pdf

[28] Noji, K. (2001). KJ Method. Second Thematic Training Course, United Nations Centre for Regional Development (UNCRD). Nagoya, Japan.
[29]Prokopska, A. (2001). Application of Morphological Analysis Methodology in Architectural Design. Acta Polytechnica, vol. 41, n. 1 .

[30] Richardson, A., Hupp, R., \& Seethaler, R. (2003). The Use of Lateral Thinking in Finding Creative Conflict Resolutions. $\quad$ Retrieved from http://www.tuti.com.au/Publications/2003/2003ABA.pdf

[31] Rossitier, J., \& Lilien, G. (1994). New "Brainstorming" Principles. Australian Journal of Management, vol. 19, issue 1 .

[32] Sample, J. (1984). Nominal Group Technique: An Alternative to Brainstorming. Retrieved from http://www.joe.org/joe/1984march/iw2.html

[33] Schilling, M. (2005). Gestione dell'innovazione. It. ed., McGraw-Hill.

[34] Schilling, M. (1998). Technological lockout: an integrative model of the economic and strategic factors driving technology success and failure. Academy of Management Review, vol. 23, n. 2 .

[35] Schoemaker, P. (1995). Scenario Planning: A Tool for Strategic Thinking. Sloan Management Review, vol. 36, issue 2 .

[36] UNIDO. (2005). UNIDO Technology Foresight Manual. Organization and Methods. Vienna, vol. 1.

[37] van Kleef, E. (2006). Consumer research in the early stages of new product development. Issues and applications in the food domain. Chapters 1-2-5, PhD thesis, Wageningen University.

[38] Watson, B., \& Radcliffe, D. (1998). Structuring Design for $\mathrm{X}$ Tool Use for Improved Utilization. Journal of Engineering Design, vol. 9, n. 3 .

[39] Yang, C., \& Fang, H. (2003). Integrating fuzzy logic into quality function deployment for product positioning. Journal of the Chinese Institute of Industrial Engineers, vol. $20, n .3$.

[40]Zhang, F. (2004). The Objectives Decision Making Study in Product Innovation Development Process Based on TRIZ Technology Evolution Theory . Retrieved from Scientific.net Materials Science and Engineering, vols. 471-472: http://www.scientific.net 